\title{
EVALUACION DEL HIPOTETICO SISTEMA DE FALLA TRANSCURRENTE ESTE-OESTE DE COSTA RICA
}

\author{
Mario Fernández Arce \\ Centro de Investigaciones Geofísicas (CIGEFI), Universidad de Costa Rica
}

(Recibido 10/7/1996; Aceptado 26/6/1997)

\begin{abstract}
The following criteria were analysed in order to evaluate the existence of the hipotetic transcurrent faults system (FTCR) of Costa Rica in its central part: geologic setting, faulting, earthquakes distribution, focal mechanisms, deep transcurrence, and gravimetric data.

The predominant faulting is the one with northwest orientation, secondly the faulting with the northeast orientation. This faulting is more abundant in the Talamanca Ridge rather than in the Central Volcanic Ridge. Faults oriented east-west, a necesary requirement for the existence of FTCR, are scarce.

The distribution of epicenters indicates that in both ridges there are seismic sources. In the Central Volcanic Ridge earthquakes take place in spaces between volcanoes. In the Talamanca Ridge there are at least five very active seismic zones. Earthquakes with more than 5-degrees in magnitud occur in both ridges. Focal mechanisms are mainly normal. Transcurrent mechanisms suggest an active faulting oriented Northwest.

There is no correlation between gravimetric lineament and the FTCR. To conclude, there is no geophysical evidence of the FTCR in the central part of Costa Rica.
\end{abstract}

\begin{abstract}
RESUMEN: Se analizaron los siguientes criterios que ayudan a evaluar la existencia de un sistema de falla mayor en la parte central de Costa Rica: configuración geológica del territorio costarricense, fallamiento, distribución de la sismicidad total del área, distribución de sismos mayores, mecanismos focales, la transcurrencia profunda y resultados de datos gravimétricos. El fallamiento predominantemente es el de orientación noroeste, seguido por el noreste. Fallas de orientación este-oeste, requisito importante para la existencia de un sistema transcurrente en la parte central de Costa Rica, son muy escasas. La distribución de sismos indica que en las dos cordilleras hay fuentes sísmicas. En la Cordillera Volcánica Central (CVC) los temblores ocurren principalmente en las depresiones ubicadas entre los macizos volcánicos. La Cordillera de Talamanca tiene mayor sismicidad que CVC y hay por lo menos cinco importantes focos sísmicos en ella. Temblores de magnitudes superiores a 5 se han registrado en ambas cordilleras. Los mecanismos focales son principalmente normales. Los transcurrentes no sugieren un fallamiento de orientación este-oeste, ni noreste, más bien indican activación de fallas con rumbo noroeste.

Se compararon lineamientos obtenidos con datos gravimétricos con el hipotético trazo de la falla transcurrente de Costa Rica pero no se encontró correlación entre ellos. Se concluye que no hay evidencia del sistema de falla transcurrente en la parte central de Costa Rica.
\end{abstract}

\section{MARCO TECTÓNICO Y ANTECEDENTES}

La tectónica de Centroamerica Meridional es gobernada por la interacción de las placas Cocos, Caribe y Nazca (Fig. 1). El límite entre Cocos y Caribe es la Fosa Mesoamericana donde la primera se introduce bajo la segunda hasta profundidades máximas de $200 \mathrm{~km}$ en Nicoya y 50 en Osa (PROTTI et al., 1994); este proceso genera esfuerzos de orientación noreste que comprimen a la
Placa Caribe. Entre Cocos y Nazca el límite es el Sistema de Fractura de Panamá el cual se compone de fallas transcurrentes de orientación nortesur. La frontera entre las placas Caribe y Nazca todavía es ambigua. Frente a las costas del Pacífico Sur de Costa Rica se localiza el Levantamiento de Cocos que arribó a la Fosa Mesoamericana hace un millón de años (LONSDALE \& KLITGORD, 1978) colisionando con la Placa Caribe y produciendo, por la menor densidad de sus rocas, un efecto boyante que se manifiesta en una menor 
profundidad de penetración de la placa suducida, disminución de la sismicidad e inhibición del vulcanismo; lo cual ha contribuido al levantamiento de la Cordillera de Talamanca (MONTERO et al., 1992). En el Caribe, frente a las costas de Costa Rica y Panamá, está el Cinturón Deformado de Panamá (BOWIN, 1976) que es un margen convergente dentro de la misma Placa Caribe, según el cual el piso de la Cuenca de Colombia se mueve hacia las mencionadas costas; en este rasgo tectónico se generan esfuerzos que comprimen solamente el sector sureste de Costa Rica, en dirección opuesta a la compresión que ocurre en la Fosa Mesoamericana. En resumen, dos márgenes convergentes, una colisión tipo dorsal-placa continental y un punto triple son los rasgos tectónicos más sobresalientes que afectan el territorio de Costa Rica, en particular el extremo sur del mismo.

En la figura 1 se muestra el trazo del hipotético sistema de falla (FTCR) según ASTORGA et al. (1991). De acuerdo a tales autores, el sistema atraviesa por la depresión central de Costa Rica, ubicada entre la Cordillera Volcánica Central y la Cordillera de Talamanca, dividiendo al país en un bloque norte que incluye las cordilleras volcánica y un bloque sur al que pertenecería la Cordillera de Talamanca. El segmento de este sistema localizado entre las dos cordilleras debería componerse de un conjunto de fallas con orientación este-oeste y de tipo sinestral. En caso de que esta estructura existiera podría definir un nuevo límite tectónico y una nueva placa que estaría entre este nuevo límite y el que actualmente forman las placas Caribe y Sudamericana.

STOIBER \& CARR (1973) se refirieron a la segmentación de la placa del Coco e indicaron que ella originaba a su vez segmentación en la placa superior. MONTERO \& DEWEY (1982) plantearon la posible existencia de una zona de cizalla a través de Costa Rica, como una alternativa para explicar la sismicidad superficial del Valle Central de Costa Rica. Estos dos trabajos fueron los únicos que contemplaron tal posibilidad durante casi 20 años. Para entonces el asunto no tenía gran trascendencia entre la comunidad científica por lo que ni siquiera era referido en artículos relacionados. A finales de la década de los 80 se toca el asunto nuevamente y es cuando ASTORGA et al. (1989) proponen formalmente la existencia del Sistema de Falla Transcurrente de Costa Rica que atravesaría el territorio costarricense desde el Océano Pacífico hasta el Mar Caribe. Tal propuesta se basó fundamentalmente en las diferencias geológicas entre las partes norte y sur de Costa Rica. Después de este trabajo y a raíz de la intensa actividad sísmica en Costa Rica a partir de 1990, en la mayoría de los estudios sismológicos relacionados con Costa Rica se empezó a mencionar esta posibilidad y a ligarlo con un límite entre el bloque de Panamá y la placa Caribe [JACOB et al. (1991), PLAFKER \& WARD (1992), GUENDEL \& PACHECO (1992), FAN et al. (1993), GOES et al. (1993), FISHER et al. (1994), PROTTI \& SCHWARTZ (1994)]. El denominador común de estos trabajos fue el análisis de mecanismos focales.

Considerando que los trabajos anteriores sobre el hipotético FTCR no reunen evidencias claras al respecto, se analizarán a continuación varios criterios que permitirán evaluar el límite tectónico propuesto por anteriores autores.

\section{CRITERIOS GEOLÓGICOS}

Según ASTORGA et al. (1991), la sección noroeste de Costa Rica es muy diferente geológicamente a la sección sureste, la primera está compuesta por cordilleras volcánicas y cuencas sedimentarias en el ante y trasarco; la segunda tiene una cordillera formada por actividad ígnea intrusiva con pocos vestigios de vulcanismo y también, cuencas sedimentarias tanto en el área antearco como en el arco trasero con fallamiento inverso en ambas. En el centro del país hay una depresión que separa ambas cordilleras y que es considerada por ASTORGA et al. (1991) como una cuenca transcompresiva (pull-apart), aunque DENYER \& ARIAS (1991) aseveran, que por el rumbo de las fallas encontradas, no son transcompresivas típicas. Estas diferencias geológicas entre uno y otro bloque no requiere de un sistema de fractura para su existencia y pueden deberse a:

1- Una fase compresiva miocénica: En el límite Mioceno-Plioceno se registra una fase compresiva (1) que afecta a Costa Rica (OBANDO et al., 1991) y lleva a la generación de magmas ácidos que ascienden y levantan la Cordillera de Talamanca. La edad de esta compresión coincide con la de la colisión del bloque de $\mathrm{Pa}$ namá con la Placa Sudamericana (2), la cual produjo levantamientos Pliocénicos en Colombia y 
12

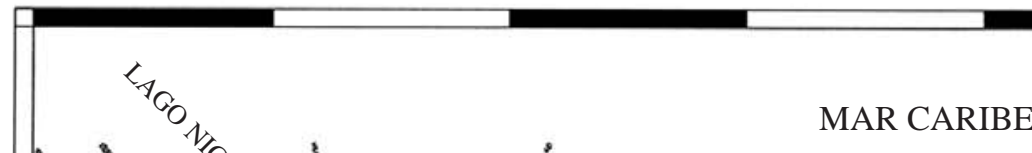

$11^{\circ}$





$10^{\circ}$

(1)



(1)

$9^{\circ}$

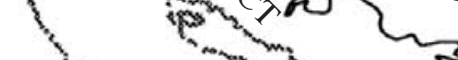

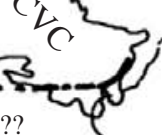

FTCR ??
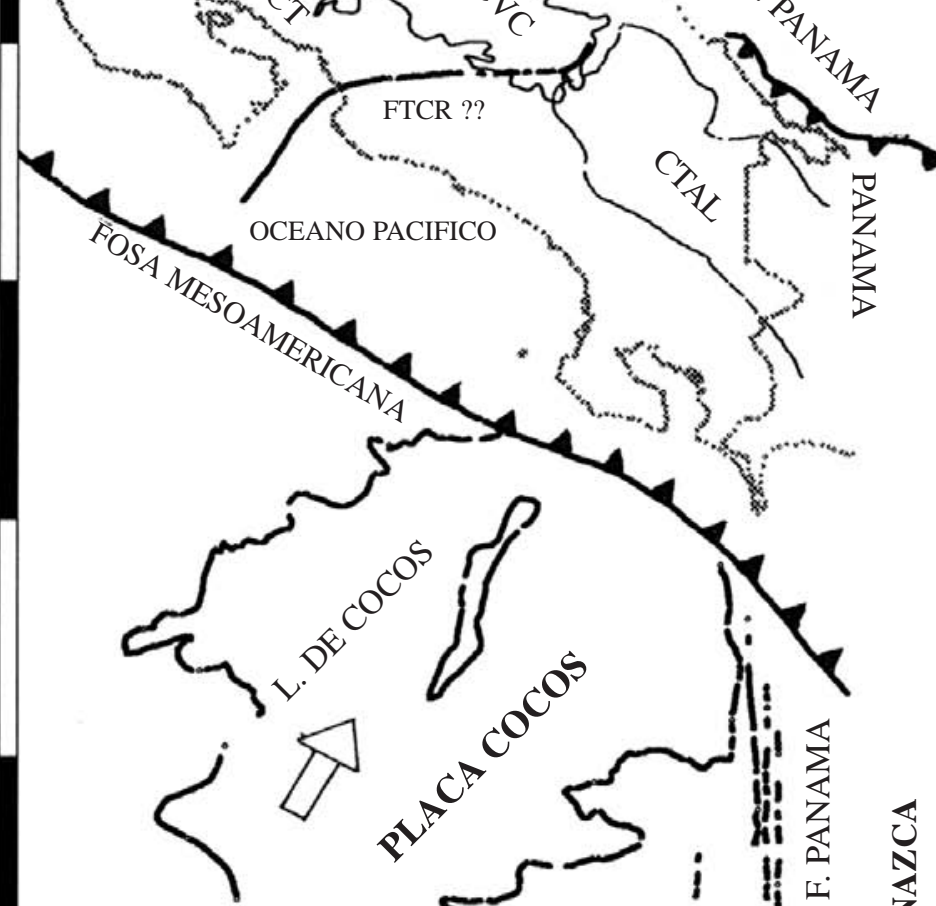

Fig. 1: Marco Tectónico. Costa Rica se encuentra en la placa Caribe, muy cerca de la Fosa Mesoamericana que es el límite entre esta placa y la placa Cocos. El contorno del territorio nacional está dado por los círculos no rellenos. Los triángulos de la Fosa Mesoamericana y el Cinturón Deformado de Panamá indican la dirección de penetración de la corteza subducida. C.D.= Cinturón Deformado, E = Escarpe, $\mathrm{P}=$ Placa, L = Levantamiento, CG = Cordillera de Guanacaste, CT = Cordillera de Tilarán, CVC = Cordillera Volcánica Central, CTAL $=$ Cordillera de Talamanca, Z.F.= Zona de Fractura y FTCR $=$ Sistema de Falla Transcurrente de Costa Rica. 
Venezuela (PINDELL \& DEWEY, 1982). Según DENYER \& ARIAS (1991) la compresión norte-sur que afectó Costa Rica en el límite Mioceno-Plioceno se debió a alguna irregularidad de la Placa Cocos con la Placa Caribe. No es fácil conciliar dos fases compresivas ( 1 y 2 ) contemporáneas, de direcciones diferentes y que afectaron regiones muy cercanas entre si como son Colombia, Venezuela, Panamá y Costa Rica, aunque por la cercanía a un punto triple, se considera que la región pudo haber experimentado compresión en más de una dirección.

2- El arribo de una dorsal a la Fosa: El arribo del levantamiento de Cocos a la Fosa Mesoamericana fue otro factor que afectó y sigue afectando al mencionado bloque, imprimiéndole una nueva fisonomía. Por él, se deformó el oeste $\mathrm{Pa}-$ namá y las regiones Atlántica y Central de Costa Rica (DENYER \& ARIAS, 1991) y la subducción se volvió somera, con lo cual no se favorece el vulcanismo y se origina un patrón de esfuerzos diferente al que existía antes de la colisión (MONTERO et al., 1992). Efectos similares han ocurrido por la subducción de otras dorsales bajo una placa (COLLOT \& FISHER, 1991; MACHARE \& ORTLIEB, 1992; HAGEN \& MOBERLY, 1994). MONTERO \& MORALES (1990) indican que las diferencias volcánicas, sismológicas y de actividad neotectónica entre la región central sureste y la región noroeste de Costa Rica se explican por la colisión del Levantamiento del Coco con la Fosa Mesoamericana y además, que por el efecto boyante de dicho levantamiento la región central sureste se levanta a mayor velocidad que la región noroeste.

De esta manera, las diferencias geológicas fundamentales entre el noroeste y el sureste de Costa Rica podrían ser explicadas tectónicamente por la actividad de un punto triple y por el arribo de un levantamiento topográfico a la Fosa Mesoamericana, estos hechos perturbaron no solamente el régimen tectónico sino también el arreglo geológico de suelo costarricense. Sin ellos, muy probablemente la sección sur de Costa Rica sería semejante a la sección norte geológicamente hablando.

\section{FALLAMIENTO}

En la figura 2, el Valle Central de Costa Rica es el área sin fallamiento aparente que incluye las ciudades de Alajuela, Heredia, San José y
Cartago. En el extremo noreste de este valle se localiza un sistema de fallas que se extiende por el flanco sur y el pie de la Cordillera Volcánica Central, de rumbo paralelo al eje longitudinal de la misma, que comienza en el flanco suroeste del volcán Irazú y termina en el flanco suroeste del volcán Poás; es este el rasgo estructural mejor definido y más sobresaliente de tal cordillera. Hacia el volcán Irazú las fallas se orientan al noroeste también, con algunas excepciones. En la depresión formada entre los volcanes Irazú y Barva hay lineamientos estructurales con rumbo norte-sur, lo mismo que al oeste del volcán Poás.

El extremo suroeste del Valle Central corresponde con el flanco noroeste y pie de la Cordillera de Talamanca, en este sector se ha localizado un sistema de fallas que se extiende desde el sureste de Cartago hasta sur de Alajuela y que también es paralelo al rumbo del eje longitudinal de la cordillera. Se distinguen varias fallas entre las que figura Higuito (Fig. 2).

El fallamiento restante se ubica en las estribaciones de la Cordillera de Talamanca (sur de la Fig. 2), que es la sección con mayor densidad de fallas de toda el área estudiada y la que cuenta con las estructuras más extensas, indicando que esta cordillera es la que se ha deformado más en los últimos períodos geológicos y quizá la que más se está deformando en la actualidad. En la figura 2 se observan dos direcciones preferenciales de fallamiento: noroeste y noreste y también, que estos sistemas se intersectan generando una forma geométrica semejante al patrón de fallas conjugado, lo que es interpretado por ARIAS \& DENYER (1991) como producto de la compresión norte-sur que afectó a Costa Rica en el Mioceno-Plioceno.

La orientación de las fallas es variable aunque predominan aquellas con rumbo sureste-noroeste, un segundo lugar tienen las fallas con dirección suroeste-noreste, luego las orientadas norte-sur y finalmente el fallamiento con tendencia este-oeste. Este último es sumamente escaso lo cual se contrapone a la existencia del sistema de falla transcurrente de Costa Rica, que en esta parte del país debería componerse de un conjunto de fallas paralelas de dirección este-oeste. El paralelismo se observa pero en las fallas surestenoroeste y prácticamente en toda la zona.

Este fallamiento no es reciente pues fallas como Tulín y Candelaria ya existían en el 


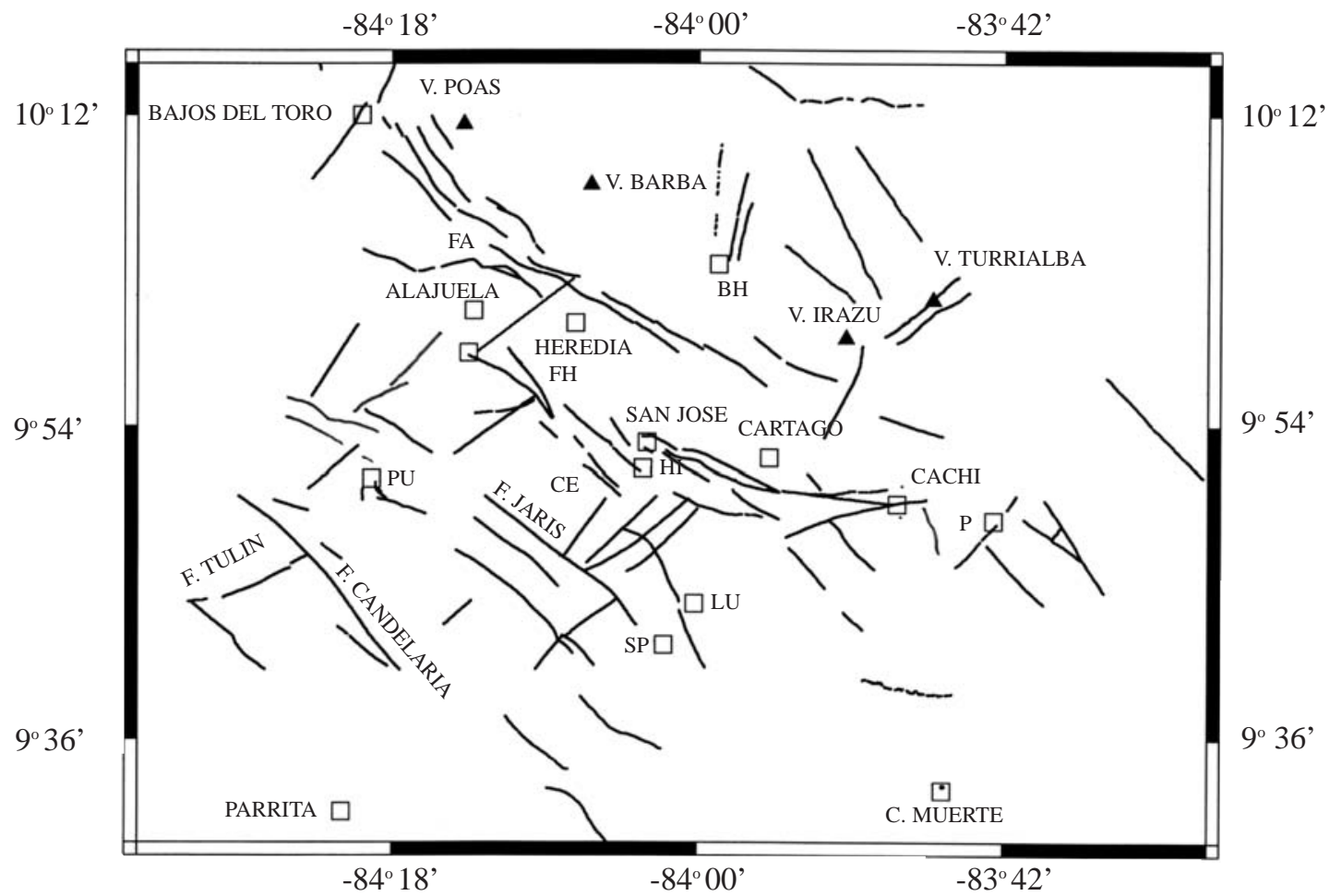

Fig. 2: Distribución de fallas mayores (trazos lineales) en la zona de estudio. P: Pejibaye, CE: Cerros de Escazú, FH: Falla Higuito, FA: Falla Alajuela, LU: La Lucha, PU: Santiago de Puriscal, SP: San Pablo de León Cortés, BH: Bajo de la Hondura, F.: falla, V.: volcán y C.: cerro.

Paleoceno-Eoceno y las fallas de orientación noroeste y noreste ubicadas en el sur del área (Cordillera de Talamanca) formaban parte de los rasgos tectónicos de esta región desde el Mioceno (DENYER y ARIAS, 1991).

\section{DISTRIBUCIÓN DE SISMOS}

En la Cordillera Volcánica Central los focos de actividad permanente se localizan principalmente en las depresiones topográficas ubicadas entre los volcanes Irazú, Barva y Poás, siendo el más activo el que se encuentra entre el Irazú y el Barva (Fig. 3). En estas dos fuentes la distribución epicentral es de tendencia noreste, en tre el Poás y el Barva, y norte-sur, entre el Barva y el Irazú. En esta última zona, los epicentros coinciden con fallas de la misma orientación, no así en la restante zona donde por lo menos una de las responsables es de rumbo noroeste. En los alrededores de la cima de los volcanes Irazú y Turrialba la actividad sísmica permanente es poca y más bien, son los enjambres sísmicos los que tienen mayor importancia como lo evidencia la actividad sísmica de 1982 y 1991. En el sistema de fallas del flanco sur de la cordillera hay sismicidad aunque no tan abundante como en las depresiones inter-volcánicas, no obstante, la acitividad sísmica sugiere que hay fallas activas en él.

En el Valle Central la actividad sísmica es mínima y se localiza al norte de Cartago, al este de San José, al sur de Heredia y sureste de Alajuela. Fallas menores, algunas no observables por ser un relleno volcánico y por la influencia antropogénica, son las responsables de estos temblores. Cerca de San José y Alajuela se han descubierto pequeñas fallas dentro del valle (Fig. 3) que en los últimos años han generado sismicidad.

El fallamiento del borde suroeste del Valle Central ha estado muy activo en el período 1990-1996, sobretodo en el sector comprendido entre el sur de Cartago y sur de Alajuela. En 


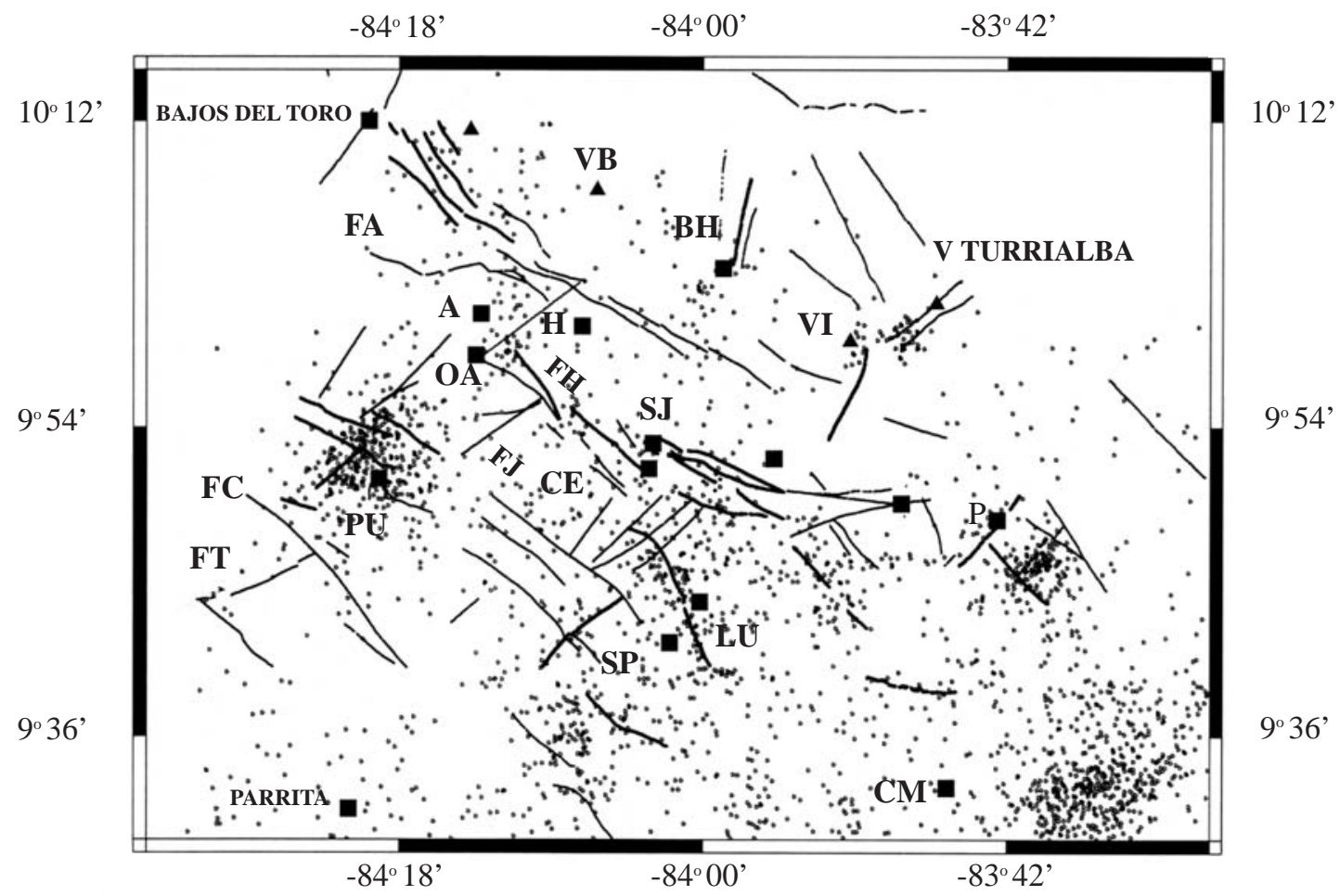

Fig. 3: Distribución de epicentros (círculos sin relleno). VP: Volcán Poás, VB: Volcán Barba, VI: Volcán Irazú, FA: Falla Alajuela, FH: Falla Higuito, FJ: Falla Jaris, FC: Falla Candelaria, FT: Falla Tulín, BH: Bajo de la Hondura, A: Alajuela, H: Heredia, SJ: San José, C: Cartago, P: Pejibaye, CE: Cerros de Escazú, SP: San Pablo de León Cortés, LU: La Lucha y CM: Cerro de la Muerte.

1992 se registró una secuencia sísmica en el extremo noroeste de tal sistema, que culminó con un evento de magnitud 4,1. En ese mismo año se registró un sismo de magnitud 4,1 y varias réplicas al suroeste de San José. En 1994 ocurrieron dos enjambres sísmicos en el tramo ubicado al sur de San José, el evento mayor de esta actividad alcanzó 4,8 de magnitud, y en 1996 se sintieron algunos sismos que se originaron en las fallas ubicadas al sur de Cartago.

Puriscal (PU) es una fuente sísmica que se activó en 1990, antes la actividad sísmica era escasa. En el transcurso de 1990 ocurrieron miles de microsismos en dicha zona y un evento mayor de 5,7 grados de magnitud. En la actualidad, las fallas de Puriscal siguen generando cierta actividad sísmica.

Los Cerros de Escazú (CE) son parte de un intrusivo que inició su ascenso en el Mioceno, tiene en su parte superior una cubierta ignimbrítica (DENYER \& ARIAS, 1991). En el presente es un foco sísmico activo, probablemente debido al comportamiento incompetente de la cobertura volcaniclástica. Fallas muy pequeñas, al igual que los temblores, serían las responsables de esta actividad. Se requieren mecanismos focales para determinar si esta sismicidad se debe al levantamiento de Talamanca o a esfuerzos tangenciales.

Al sur de Cartago se localiza uno de los focos sísmicos más importantes de la región central del país, el área conocida como Zona de los Santos, donde la sismicidad es abundante y permanente. El mayor evento registrado en esta zona es de magnitud 4,8, en 1991.

En Pejibaye (P) el fallamiento predominante es de rumbo noroeste. Estas fallas se activaron en 1993 y generaron muchos temblores, siendo los de mayor magnitud: 4,8, 4,9 y 5,3. Esporádicos temblores siguen ocurriendo en la zona.

Cuericí (al este de CM) es una zona sísmica ubicada casi en la cima de la Cordillera de Talamanca y es uno de los focos sísmicos más 
activos del país. En 1983 se detectó un sismo de magnitud 6,1 (Ms) en esta zona y otro de 5,6 en abril de 1991. El material deformado probablemente sea la cobertura sedimentaria que sobreyace el Intrusivo de Talamanca. Por lo inaccesible del terreno y la densa vegetación que lo cubre no ha sido posible cartagrafiar adecuadamente el fallamiento. Es recomendable instalar más instrumental sísmico en esta área para entender mejor su sismicidad y los procesos tectónicos que están afectando a la Cordillera de Talamanca.

En síntesis, la sismicidad, al igual que el fallamiento, es más intensa al sur del área estudiada, donde hay por lo menos cinco focos símicos de gran actividad. En la Cordillera Volcáncia Central los temblores son más escasos y se concentran principalmente en las depresiones ubicadas entre los volcanes.

\section{SISMOS HISTÓRICOS Y RECIENTES IMPORTANTES}

En el registro histórico hay diez temblores de la zona con magnitudes mayores a 5, documentados y estudiados. Recientemente, en el período 1990-1993, han ocurrido seis temblores más en el área. En forma grosera, se alinean con una orientación sureste-noroeste, paralela al eje longitudinal de las cordilleras Volcánica Central y Talamanca. La mayoría de tales sismos se ha ubicado en los flancos sur y noreste de tales cordilleras, respectivamente, donde hay importantes fallas de orientación noroeste. A continuación se analizarán estos sismos junto al fallamiento.

Los eventos históricos de 1851, 1888, 1912 (esquina superior derecha, Fig. 4), 1952 y 1955 ocurrieron en el fallamiento de la Cordillera Volcánica Central. Algunos de estos eventos se acompañaron de retumbos (ALVARADO et al., 1988) y sus áreas mesosísmicas sugieren fallamiento tanto transversal $(1912,1952$ y 1955) como paralelo al eje de la cordillera (1851 y 1888) [MONTERO \& MORALES,1988], lo cual es coherente con el fallamiento en la cercanía de los epicentros, excepto para el evento de 1952 cuya área mesosísmica está orientada en sentido noreste mientras que las fallas del entorno son de rumbo noroeste. Esta actividad refuerza la hipótesis de que el fallamiento en esta cordillera está activo; nótese como los epicentros de este sistema se distribuyen a lo largo del mismo (Fig. 4).
Al sureste de San José y Cartago MONTERO \& MORALES (1988) han ubicado, macrosísmicamente, cinco temblores históricos. Dichos autores indican que las áreas mesosísmicas están elongadas tanto hacia el noroeste como hacia al noreste. Al igual que en la Cordillera Volcánica Central, en este sector, que corresponde con el flanco noreste de la Cordillera de Talamanca, hay importantes fallas de orientación similar a la dirección de elongación de las áreas mesosísmicas.

El sismo de 1983 fue de magnitud 6,1 (Ms) y ocurrió en julio de ese año; en abril había ocurrido un terremoto en la costa pacífico sur, al sureste del epicentro. De acuerdo al PDE (Preliminary Determination of epicenters, NEIC) de julio de 1983, el mecanismo de falla del evento principal fue normal con una gran componente horizontal; los planos nodales reportados son: N5E y N90E. GÜENDEL (1986) obtuvo un mecanismo focal transcurrente con componente normal para el evento principal. El escaso fallamiento de la zona favorece un mecanismo con un plano nodal orientado al norte o ligeramente al noroeste.

El evento de 1990 fue el mayor de la abundante actividad sísmica que ocurrió en Puriscal entre abril y diciembre de ese año. Fue un temblor de magnitud 5,7 que ocurrió en una zona donde hay fallas con orientación noreste y noroeste, con predominio de las segundas (Fig. 4). El mecanismo focal del evento es transcurrente con una componente de desplazamiento inverso (PDE diciembre 1990, ROJAS en BOSCHINI \& BARQUERO,1990, FERNANDEZ, 1995). El plano que mejor satisface las soluciones focales es el de rumbo noreste, razón por la cual se atribuye este temblor a una falla en esta dirección. Se determinó que no fue una sola falla la que produjo tal actividad sísmica sino la mayoría de aquellas ubicadas en las inmediaciones del epicentro del evento analizado en este párrafo (FERNANDEZ, 1995).

En abril de 1991 ocurrió el Terremoto de Limón en la zona atlántica de Costa Rica y dos días después se registró el evento numerado 1991a (Fig. 4), muy cerca del punto donde ocurrió el evento de 1983. La magnitud del evento fue 5,6 y es, junto con el de 1983, de los mayores temblores que se han registrado en la cordillera de Talamanca. El mecanismo focal reportado por el PDE (abril 1991) indica que el desplazamiento en la falla que originó el sismo es de tipo transcurrente. 


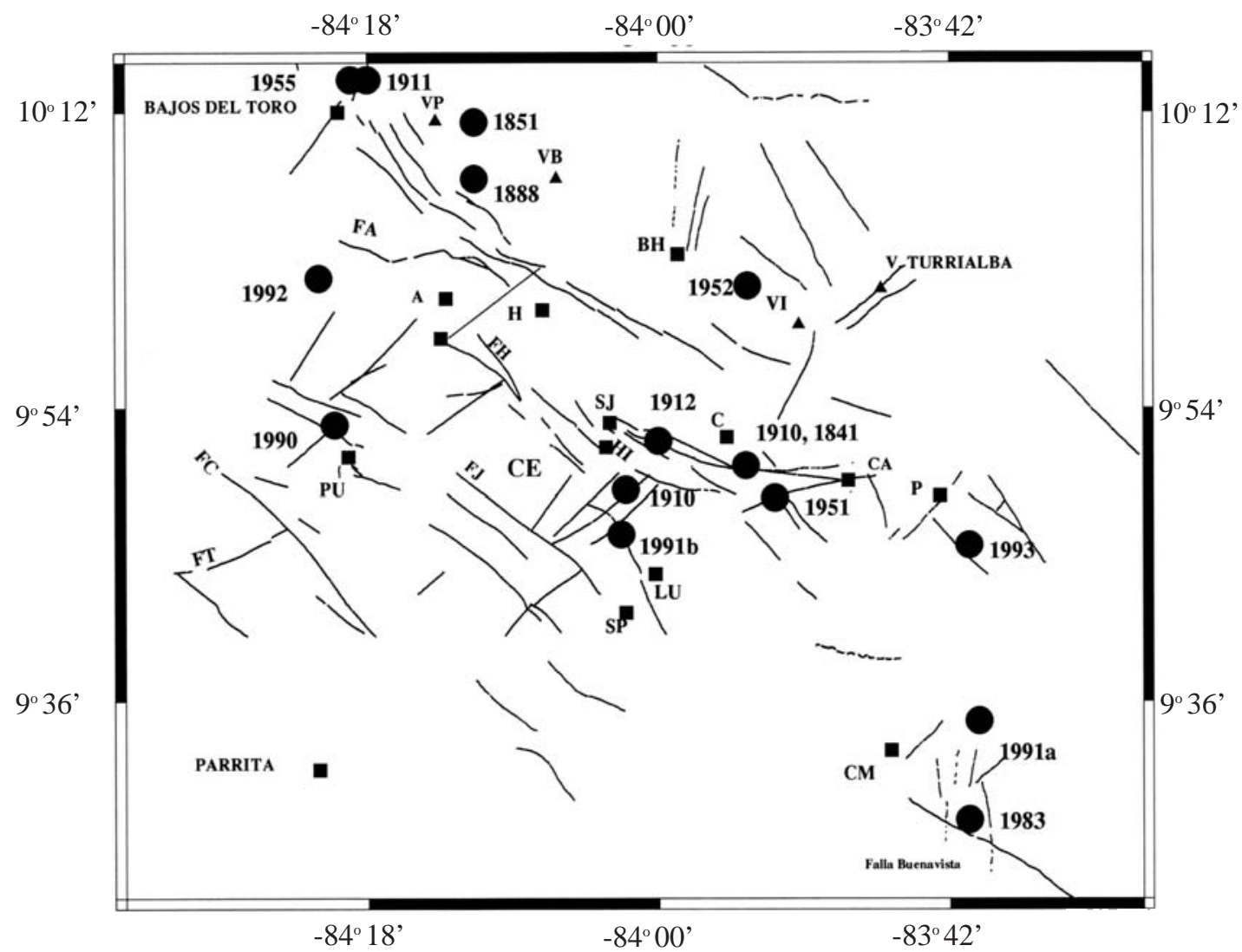

Fig. 4: Distribución de fallas y sismos importantes en la zona de estudio. Los círculos negros representan los sismos; se agrega el año en que ocurrieron a la par de los epicentros.

En agosto de 1991 se localizó un sismo (Md 4,8) al sursureste de San José (Fig. 4). Las réplicas se distribuyeron a lo largo de la falla de dirección noroeste sobre la cual está el epicentro. El mecanismo focal de tal temblor (PDE agosto 1991) es transcurrente con un plano que coincide con dicha falla.

El evento de 1992 fue de magnitud 5,7 y se ubicó a una profundidad de $87 \mathrm{~km}$. Pese a su profundidad, sacudió fuertemente el sector central del país, provocando pánico general y caída de objetos. Por tales efectos, este temblor probablemente se habría catalogado como superficial si no se hubiera localizado instrumentalmente; esto obliga a mantener mucha cautela a la hora de interpretar la sismicidad histórica sobretodo si se utiliza para investigar alineamientos sísmicos o estructurales. El mecanismo focal de este muestra una importante componente de movimiento transcurrente (PDE marzo 1992).

En 1993 ocurrió una secuencia sísmica en Pejibaye de Turrialba (P en Fig. 4), una zona con fallamiento preferentemente noroeste. Los tres eventos mayores de esta actividad tienen por solución focal un mecanismo transcurrente con un plano de orientación noroeste común a los tres. Además, estos tres eventos se alinean de sureste a noroeste. Lo anterior sugiere que el fallamiento de rumbo noroeste fue activado.

En resumen, los sismos históricos de la región central de Costa Rica se han localizado en dos sistemas de fallas bien definidos: el flanco sur de la Cordillera Volcánica Central de edad cuaternaria y el flanco noreste de la Cordillera de Talamanca. En la zona ocurren también sismos profundos que llegan a sentirse. Algunos 




Fig. 5: Distribución de fallas y mecanismos focales.

temblores están ocurriendo en fallas terciarias de orientación noroeste, en el sureste del área, incluyendo las estribaciones de la Cordillera de Talamanca.

\section{MECANISMOS FOCALES}

Para este trabajo se utilizaron los mecanismos focales de calidad A de FERNANDEZ (1995), hechos con el Focmec del SEISAN SYSTEM (HAVSKOV \& LINDHOLM, 1992) y buscando soluciones cada cinco grados. También se incluyen los mecanismos de sismos que ocurrieron dentro de la zona estudiada y que aparecen reportados en el PDE y cinco más del período 1995-1996 que son parte de la base de datos de la Red Sismológica Nacional.
La figura 5 muestra los mecanismos focales y su ubicación en el área estudiada; como se puede apreciar, la distribución de mecanismos abarca casi toda el área de estudio donde hay sismicidad, lo cual garantiza una buen muestreo. Se desprende de la figura que los tres tipos de mecanismos focales (normal, inverso y transcurrente) se dan en la zona, con predominio de los normales, seguidos por oblicuos e inversos.

La diversidad de mecanismos focales en áreas muy pequeñas como Puriscal (PU) y Pejibaye $(\mathrm{P})$ sugieren gran debilidad cortical y complejidad tectónica. Lo más probable es que una falla induce movimiento en otras complicando los deslizamientos sobre sus planos. Aparte de ello, la inestabilidad posterior a un evento grande puede producir diversidad de mecanismos focales. 
Aunque en este trabajo apenas se incluyen seis mecanismos focales de la Cordillera Volcánica Central, el movimiento inferido de esos mecanismos es fundamentalmente vertical, más distensivo que compresivo. No obstante, es necesario recopilar más mecanismos para ratificar esta deducción preliminar.

Al sur del Valle Central (Cordillera de Talamanca) la transcurrencia es mayor. Pese a que los mecanismos de tipo transcurrente no superan en número a los de tipo normal, temblores de mayor magnitud son los que mayor movimiento horizontal muestran, veanse los cercanos a $\mathrm{P}$, LU, CM y PU; en los casos de Puriscal y Pejibaye tales mecanismos tienen altas componentes de movimiento inverso, a diferencia de los normales cuyo desplazamiento vertical es muy puro.

Respecto a la orientación de las fallas sugeridas por los mecanismos focales, se indica que los tres mecanismos transcurrentes (los más grandes) cercanos a P, están acorde con un fallamiento de dirección noroeste al igual que el existente; nótese también que la distribución espacial de tales temblores es consistente con los datos anteriores. El mecanismo transcurrente cercano a LU se ubica sobre una falla de rumbo noroeste y las réplicas de ese evento se alinearon a lo largo de la misma, razón por la cual hay certeza de que ella produjo el temblor en cuestión y se movió horizontalmente. El mayor mecanismo de la figura 5, ubicado al este de CM, es del evento de 1983 y según el PDE (julio 1983) corresponde con una falla normal con una alta componente transcurrente, aunque por el alto ángulo de buzamiento de los planos reportados y los valores del vector deslizamiento (rake) el movimiento fue más horizontal que vertical; el epicentro de este temblor se ubicó entre dos fallas de orientación ligeramente noroeste que concuerda con el rumbo del plano noroeste del mecanismo. La falla localizada a la derecha del epicentro se denomina Buenavista y a ella BOSCHINI et al. (1988) atribuyen tal temblor.

En síntesis, los datos de las soluciones focales de temblores con magnitud superior a 3 revelan que el fallamiento predominante en el área es de tipo normal, con una importante componente transcurrente en temblores mayores, principalmente al sureste de la zona que abarca áreas altas de la Cordillera de Talamanca. La correlación entre mecanismos focales y fallas brinda clara evidencia acerca de movimientos transcurrentes en fallas de orientación noroeste, lo cual se contrapone al sistema de falla transcurrente de Costa Rica, que según lo propuesto, debe ser de rumbo este-oeste, a lo sumo noreste, pero no noroeste.

Por haber muchos mecanismos que sigieren movimiento oblicuo en las fallas, se utilizó la representación triangular (Fig. 6) de una solución de mecanismo focal (FROLHLICH \& APPERSON, 1992), la cual está basada en la geometría del tensor de esfuerzos y en el buzamiento de los ejes; en los vértices del triángulo se encuentran los campos de los deslizamientos transcurrente (transc.), normal (nor.) e inverso (inv.) puro y hacia el centro del triángulo está el campo de los deslizamientos oblicuos. Según la figura 6, la mayoría de las soluciones focales representadas en ella corresponden con deslizamientos de tipo normal, el resto son mecanismos inversos puros y oblicuos en cantidades similares de uno y otro tipo. De la muestra analizada solamente se obtuvo un mecanismo transcurrente puro lo que indica que la transcurrencia derivada de estos mecanismos focales se debe a movimiento combinado (vertical y horizontal) y no a transcurrencia pura.

WHITE \& HARLOW (1993) estudiaron los sismos corticales destructivos de America Central a partir de 1900, encontrando que tal sismicidad se concentra en el frente volcánico el cual consideran como una zona de deslizamiento dextral dirigida por la subducción oblicua. Grandes temblores como los de Managua de 1931 y 1972 fueron transcurrentes lo mismo que el del Golfo de Honduras en 1982 y de Tilarán, Costa Rica, en 1973 (este último lejos de la parte central del país). Estos datos son evidencia de que la trascurrencia en la placa Caribe no se concentra en Costa Rica sino que está presente en otros sectores del margen Cocos-Caribe.

\section{LA TRANSCURRENCIA EN LA SISMICIDAD DE PROFUNDIDAD MAYOR A $30 \mathrm{~km}$}

Aunque en este trabajo se estudia la sismicidad superficial (0-30 km), se incluye aquí esta sección porque al igual que la sismos de foco superficial, los de profundidad intermedia están ocurriendo principalmente en la parte central del país y sus mecanismos focales también muestran trancurrencia. Establecer una relación directa entre los 


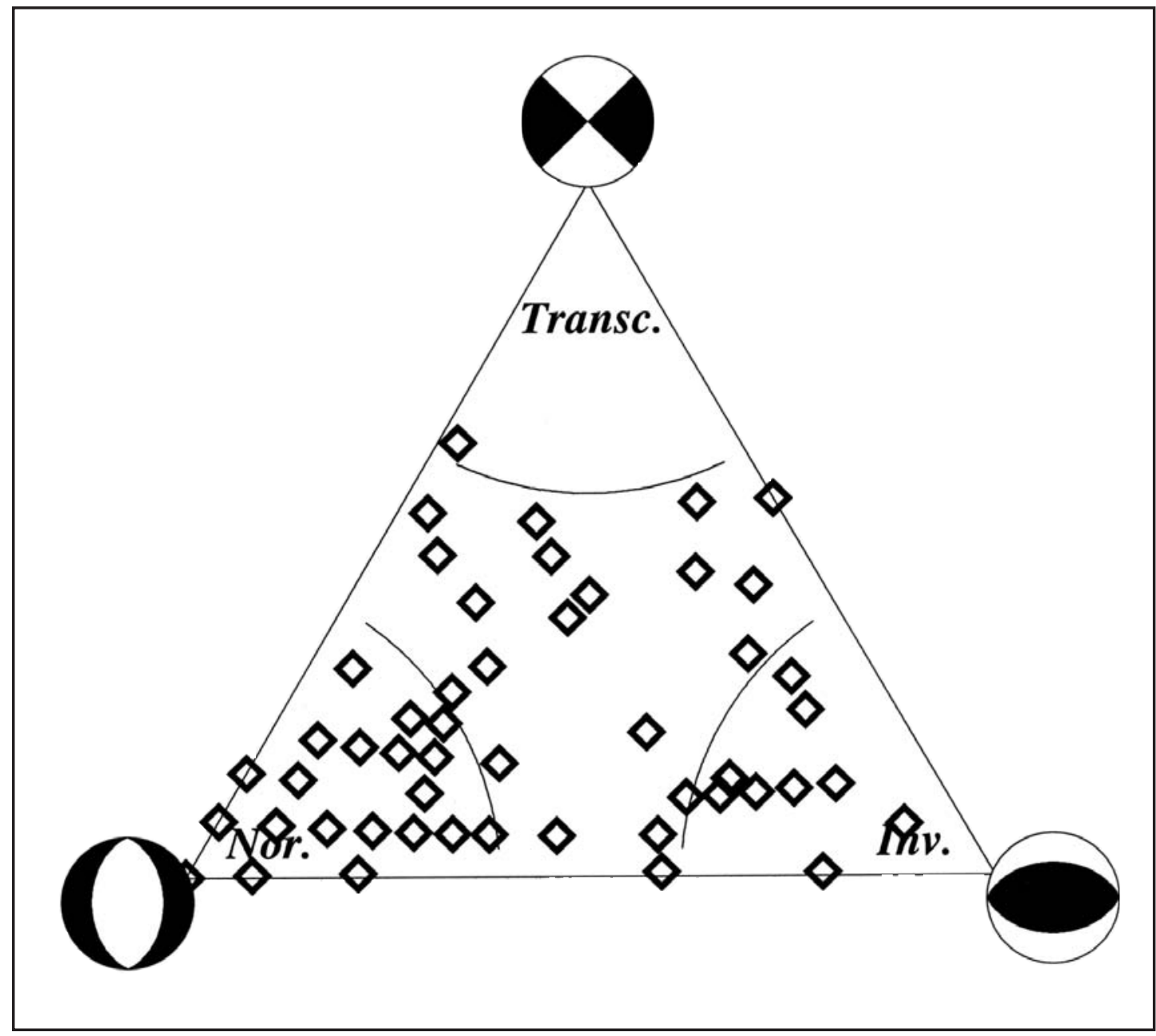

Fig. 6: Representación triangular de la solución de un mecanismo focal (FROHLICH \& APPERSON, 1992). En los vértices están los campos de deslizamiento puro. Transc.: transcurrente, Nor.: normal, Inv.: inverso. Los rombos representan las soluciones focales de los temblores.

procesos superficiales y aquellos de profundidad intermedia requiere analizar con mayor detalle ambos sistemas. Lo que si se puede afirmar es que el proceso tectónico actual es más intenso (según la sismicidad) en la parte central de Costa Rica y esto, más las presiones generadas por el choque entre el Levantamiento de Cocos y la Placa Caribe, está originando más deformación en el centro-sur del territorio costarricense. Entonces, la sismicidad superficial y la de profundidad intermedia están vinculados por los procesos tectónicos que se originan en la Fosa Mesoamericana.
La figura 7 muestra la sismicidad de profundidad mayor a $30 \mathrm{~km}$ para Costa Rica durante el período 1990-1993. Se nota muy claramente que la mayor actividad está concentrada en el sector central del país y que es muy abundante; tanto en diciembre de 1994 como en el mismo mes de 1995 se detectaron sismos de subducción con réplicas (en ambos meses los sismos se sintieron en gran parte del país) en el área correspondiente a la mancha más oscura de la figura. Además, hay seis concentraciones dentro de la gran mancha negra mayor, que representan fuentes sísmicas 


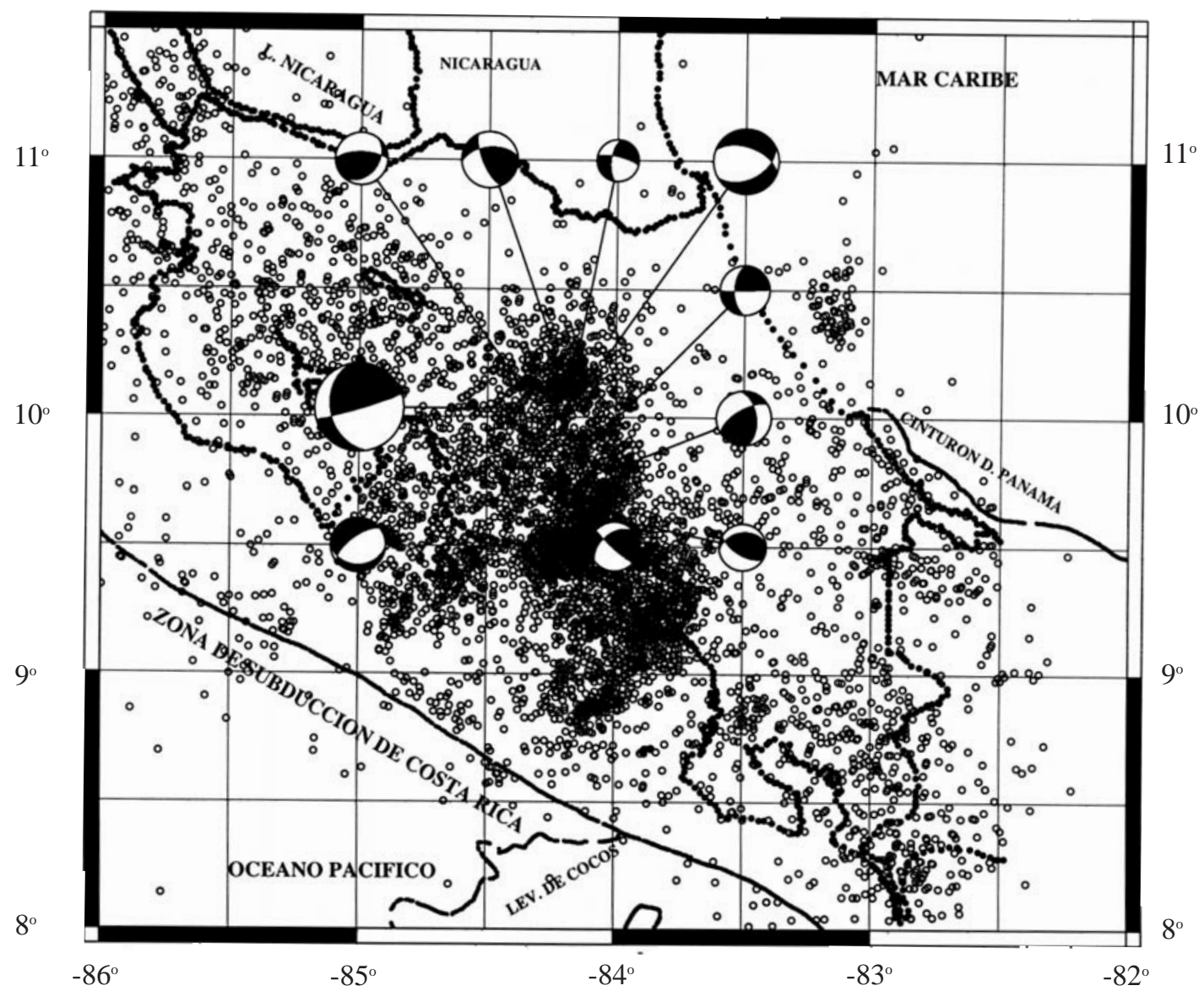

Fig. 7: Distribución epicentral de sismos de profundidad intermedia que ocurrieron durante el período 1985-1995. Se han incluído en este trabajo porque indican que el proceso tectónico se está manifestando con gran intensidad en la parte central del país y porque sus mecanismos muestran alta componente transcurrente, lo cual podría repercutir en la actividad superficial. El rango de profundidad varía entre 0 y $200 \mathrm{~km}$.

muy activas de profundidad intermedia. En la zona que comprende la concentración con centro en $10.5^{\circ}$ y $84.5^{\circ}$ ocurrió, en 1992 , un sismo de magnitud 5,7 a $87 \mathrm{~km}$ de profundidad (sismo de Naranjo) que fue sentido muy fuerte en toda el área central del país, y luego siguieron réplicas como si se tratara de una ruptura cortical.

Se seleccionaron 10 mecanismos focales de sismos con profundidades entre 30 y $107 \mathrm{~km}$ (Fig. 7), ellos indican una alta componente de movimiento transcurrente. con ellos. El de mayor magnitud corresponde al sismo de Naranjo (marzo de 1992) y como se ve en la figura 7 , es inverso con importante componente transcurrente y concuerda ligeramente con el mecanismo hecho por Harvard pero difiere de los reportados según ondas $\mathrm{P}$ y el tensor de momento (PDE marzo 1992). Hay también mecanismos de tipo inverso y normal. En la tabla 1 se dan los datos de ubicación de los sismos profundos y su mecanismo focal.

La concentración de sismos en la parte central de Costa Rica y la transcurrencia de los mecanismos focales se interpretan como el resultado de la introducción de corteza oceánica rugosa, quizá promontorios desarrollados al pie del Levantamiento de Cocos, bajo la placa Caribe. 
Tabla 1

Datos de mecanismos focales de profundidad intermedia

\begin{tabular}{|c|c|c|c|c|c|c|c|c|c|c|c|}
\hline & Fecha & Hora & Lat. & Lon. & Prof. & Mag. & $\mathrm{Rms}$ & Erln & Erlt & Erdp & $\mathrm{Cob}$ \\
\hline 1 & 070392 & $01: 53$ & 10,04 & 84,362 & 78 & 5,6 & 0,22 & 1,3 & 3,1 & 3,6 & 125 \\
\hline 2 & 070392 & $05: 58$ & 10,12 & 84,367 & 77 & 3,3 & 0,32 & 1,5 & 2,4 & 2,4 & 186 \\
\hline 3 & 120992 & 08:36 & 9,491 & 84,248 & 49,5 & 3,5 & 0,11 & 0,7 & 0,8 & 1,7 & 33 \\
\hline 4 & 230193 & $00: 33$ & 10,23 & 84,231 & 107 & 3,6 & 0,27 & 1,9 & 1,8 & 2,6 & 153 \\
\hline 5 & 210893 & $17: 05$ & 9,818 & 83,955 & 76,8 & 3,5 & 0,12 & 0,8 & 1,0 & 0,9 & 57 \\
\hline 6 & 230893 & $15: 33$ & 10,20 & 84,121 & 103,5 & 2,7 & 0,14 & 0,9 & 0,9 & 1,0 & 140 \\
\hline 7 & 151193 & $14: 01$ & 9,830 & 84,181 & 52 & 3,2 & 0,17 & 1,2 & 1,1 & 2,0 & 88 \\
\hline 8 & 240394 & $19: 13$ & 9,633 & 84,100 & 32 & 3,0 & 0,30 & 1,0 & 1,1 & 1,2 & 51 \\
\hline 9 & 240394 & $19: 38$ & 9,650 & 84,089 & 34 & 3,2 & 0,31 & 0,9 & 1,0 & 1,1 & 52 \\
\hline 10 & 210495 & 08:59 & 10,24 & 84,032 & 70 & 4,2 & 0,39 & 3,2 & 4,4 & 3,9 & 213 \\
\hline $\mathrm{N}^{\circ}$ & Az. & Buz. & Ad & Ep & Ip & $\mathrm{Et}$ & It & Pol & Epol & Sols & Q \\
\hline 1 & 168,7 & 35,5 & 7,1 & 134 & 31,8 & 14,4 & 38,9 & 11 & 1 & 60 & $\mathrm{C}$ \\
\hline 2 & 37,8 & 34,8 & 42,2 & 341,3 & 18 & 219,3 & 58,4 & 11 & 0 & 40 & B \\
\hline 3 & 89 & 28,9 & $-57,6$ & 114,6 & 65,2 & 335,4 & 19,3 & 10 & 0 & 4 & A \\
\hline 4 & 264,2 & 52,2 & 26,6 & 214,3 & 10,6 & 114,3 & 43,1 & 10 & 0 & 33 & B \\
\hline 5 & 352,4 & 51,1 & 34,4 & 298,5 & 7,6 & 199,7 & 49 & 10 & 0 & 26 & A \\
\hline 6 & 186,3 & 64,3 & $-16,1$ & 147,2 & 28,9 & 53.1 & 7,44 & 11 & 0 & 26 & A \\
\hline 7 & 181,1 & 55,2 & 3,5 & 140,5 & 21,6 & 39,3 & 26,1 & 8 & 0 & 55 & $\mathrm{C}$ \\
\hline 8 & 259,4 & 35,5 & 53,9 & 194,8 & 14,1 & 71,9 & 65,2 & 10 & 0 & 5 & A \\
\hline 9 & 229 & 45,9 & 9,9 & 188,7 & 23,9 & 80,3 & 35,4 & 11 & 0 & 16 & A \\
\hline 10 & 289,5 & 54 & $-58,7$ & 258,3 & 64,5 & 357,8 & 4,53 & 12 & 0 & 58 & B \\
\hline
\end{tabular}

Esto, aunado a la mayor velocidad de convergencia de las placas en el Pacífico Central de Costa Rica (con respecto al Pacífico Norte), genera un campo de esfuerzos diferenciales y posiblemente algún fracturamiento en las protuberancias de la placa subducida. La transcurrencia observada en sismos de profundidad intermedia podría deberse a lo anterior. Es probable que cada uno de los agrupamientos sísmicos de la figura 6 tenga una aspereza asociada.

En el noroeste de Costa Rica, la placa se subduce con gran ángulo pero con una alta componente de deslizamiento asísmico (McNALLY \& MINSTER, 1981 en MONTERO \& MORALES, 1984) y menor velocidad que en las restantes áreas del país. Por lo anterior y por la subucción de litósfera con poco relieve, la sismicidad es muy baja en ese sector del país. En el extremo sur de Costa Rica, falta la sismicidad intermedia y profunda debido a que la menor edad y densidad de las rocas del Levantamiento de Cocos produce un efecto boyante (GUENDEL, 1986) que dificulta la introducción de la corteza oceánica bajo la continental y consecuentemente, el vulcanismo y la sismicidad intermedia-profunda son bajos. Esta situación tectónica en el sur del país crea condiciones aptas para que por lo menos en la Placa Cocos haya transcurrencia; si el Levantamiento de Cocos tiende a flotar, inhibiendo la penetración de la placa, debería haber una zona cercana al pie de tal levantamiento que sería el límite entre dos segmentos de placa con diferente velocidad de penetración y aunque no haya fractura, si debe existir un campo diferencial de esfuerzos que favorecería una transcurrencia a nivel de la placa subducida. Pero, considerando que el Levantamiento de Cocos colisiona con la Placa Caribe, en superficie ocurriría algo similar por la presión del levantamiento más sin ocurrir fracturamiento por estar de por medio un plutón de raíz profunda. No obstante, las formaciones sedimentarias sobre el plutón son afectadas por los esfuerzos generados y sus fallas son activadas originando gran sismicidad. COATES et al. (en prensa), indican que el incremento en la tasa de emergencia de Limón y Bocas del Toro desde 90 $\mathrm{m} / \mathrm{m}$.a hasta $156 \mathrm{~m} / \mathrm{m}$.a hace $1.6 \mathrm{~m}$.a es consecuencia de la penetración del Levantamiento de Cocos bajo la Placa Caribe.

\section{RELACIÓN CON DATOS GRAVIMÉTRICOS}

PONCE \& CASE (1987) hicieron un mapa de anomalía de Bouguer completa para Costa Rica con anomalías de aire libre en alta mar. Como 
parte del procesamiento de los datos, a los mismos se le aplicó la corrección del terreno que compensa para la diferencia entre la elevación de las estaciones. Las principales anomalías encontradas se localizan en la Península de Nicoya (positiva) y en las cordilleras Volcánica Central y Talamanca (negativas) [MONTERO et al., 1990].

Se destaca en este trabajo un prominente lineamiento gravimétrico con rumbo noreste, que separa las partes norte y sur de Costa Rica. Indican los autores que el mismo puede ser la expresión de una zona de fractura mayor y lo correlacionan con una difusa faja de fallas con rumbo noreste, extendida desde Quepos hasta la cuenca de Limón, el límite meridional de los grandes aparatos volcánicos cuaternarios y un gap sísmico.
En la figura 8 se ha incluído el lineamiento propuesto por PONCE \& CASE (1987), el Sistema de Falla Transcurrente de Costa Rica (ASTORGA et al., 1991) y el área que abarca este estudio. El área se incluye para determinar por cuales sectores de la misma se extienden los lineamientos. Se observa que el alineamiento gravimétrico no corresponde con el Sistema de Falla Transcurrente propuesto por ASTORGA et al. (1991), por su ubicación espacial serían dos estructuras diferentes. En su estudio gravimétrico, PONCE \& CASE (1987) no encontraron evidencia de fracturamiento de dirección E-O a lo largo de la depresión central de Costa Rica.

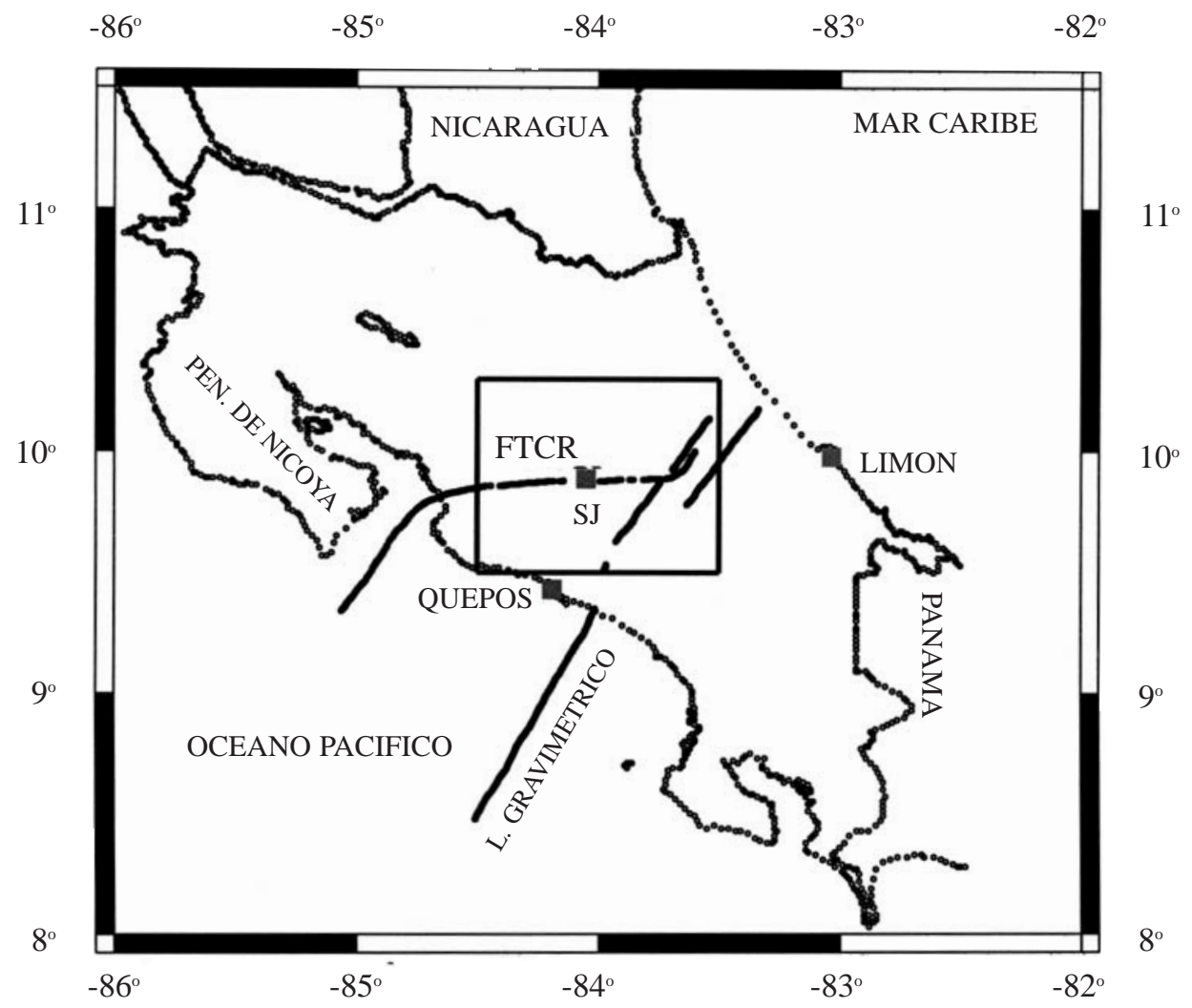

Fig. 8: Fracturamientos propuestos en la parte central de Costa Rica: La Falla Transcurrente de Costa Rica (FTCR) y el lineamiento gravimétrico de PONCE y CASE (1987). El recuadro corresponde con el área estudiada en este trabajo. 


\section{ANÁLISIS Y CONCLUSIONES}

No se encontraron evidencias que apoyen y caractericen el sistema de falla transcurrente en la parte central de Costa Rica. Hay mecanismos focales de tipo transcurrente, pero se considera que no definen una zona de cizalle en la parte central de Costa Rica. Hay transcurrencia en la región central de Costa Rica, pero no solamente superficial sino también intermedia, lo que se considera es el resultado de la combinanación de cuatro factores: 1-La convergencia oblicua entre Cocos y Caribe (WHITE, 1991), 2-El choque del Levantamiento de Cocos con la Placa Caribe, 3Un campo de esfuerzos diferenciales derivado de la introducción de montes marinos bajo la placa Caribe y, 4-la diferencia de penetración entre el Levantamiento de Cocos y el resto de la placa Cocos. Lo primero y lo segundo repercuten sobre la transcurrencia superficial que existe en toda Centroamérica (WHITE, 1991). Lo tercero y cuarto provoca la trascurrencia profunda y podría estar llevando a la deformación por fracturamiento de los montes sumergidos, incluso hasta llegar a actividad persistente como fue el caso de la actividad intermedia de Naranjo, en marzo de 1992. Como la subducción es más intensa por la mayor velocidad de convergencia entre el Golfo de Nicoya y Quepos, la penetración es más vigorosa y por esto la alta sismicidad observada actualmente en el país. El indentor de Cocos (MONTERO, 1994) y su colisión con la placa Caribe (SUAREZ et al., 1995) deben estar transmitiendo esfuerzos no solamente hacia el noreste del país sino también hacia el centro, lo cual podría ser la causa de la alta sismicidad en la misma cresta de la Cordillera de Talamanca y en particular, en las fallas de orientación noroestesureste como aquellas de Pejibaye.

FISHER et al. (1993) indican que los sismos posteriores a los terremotos de Cóbano y Limón están restringidos a una difusa zona de fallamiento diverso y de orientación este-oeste a lo largo del Valle Central de Costa Rica y que la variedad de fallas pueden reflejar un estado temprano de una zona de cizalla en desarrollo. En este trabajo se han incluído todas las fallas y lineamientos sugestivos de fallas y se ha encontrado que el patrón de fallamiento de la zona es el mismo que ARIAS \& DENYER (1991) derivaron de la compresión norte-sur que afectó a Costa Rica en el límite Mioceno-Plioceno. Las ubicaciones epicentrales y los mecanismos focales indican que hay actividad sísmica tanto en fallas de orientación noreste como en las de orientación noroeste, pero principalmente es estas últimas. Por lo tanto, la sismicidad de la zona aludida por FISHER et al. (1993) no se debe a fallamiento incipiente sino a fallamiento preexistente reactivado por la colisión del levantamiento de Cocos con la Placa Caribe (DENYER \& ARIAS, 1991) y por la desestabilización que ocasionan los grandes terremotos.

De acuerdo a este estudio, hay movimiento tanto en fallas de rumbo noroeste como noreste; el temblor de Puriscal del 22 de diciembre de 1990 y los de Desamparados en 1994 sugieren fallamiento NE y los de Pejibaye (10 de julio, 1993) y Corralillo (9 de agosto de 1991) son de transcurrencia en sentido NO. Ante esta diversidad de orientaciones de las fuentes sísmicas, la sismicidad de la parte central de Costa Rica, no constituye un alineamiento mayor unidireccional.

Durante el período 1984-1989 se registraron 1847 ( 1 < mag. < 5) eventos para un promedio de 263 sismos por año. En el período 19901994 el número de eventos se incrementó debido a la ocurrencia de grandes temblores en el borde pacífico y caribe del territorio nacional, que desestabilizaron los sistemas de fallas y con ello indujeron mucha sismicidad. La mayoría de estos temblores son de magnitud inferior a 3 grados. La intermitencia de los picos de máxima actividad entre períodos de relativa quietud responden a la reactivación de zonas de debilidad cortical por las ondas de deformación asociada a los grandes temblores. En ausencia de tales disturbios, la sismicidad detectada es de muy baja magnitud y moderados niveles de ocurrencia, excepto en la zona de los Santos y Cuericí donde el nivel de ocurrencia siempre es alto.

\section{AGRADECIMIENTOS}

Se agradece al INTERNATIONAL DEVELOPMENT RESEARCH CENTRE (IDRC) de Canadá por facilitar los recursos económicos para desarrollar con éxito esta investigación. También, nuestro sincero agradecimiento al personal de la Oficina Regional del IDRC para América Latina y el Caribe (LACRO) y al del Instituto Panamericano de Historia y Geografía (IPGH) por su gran colaboración y amistad durante la investigación. 


\section{BIBLIOGRAFÍA}

ANGELIER, J., 1979: Determination of the Mean Principal Stresses for a Given Fault Population. - Tectonophysics, 56: 17-26.

ALVARADO, G., MORALES, L. D., MONTERO, W., CLIMENT, A. \& ROJAS, W., 1988: Aspectos sismológicos y morfotectónicos en el extremo occidental de la Cordillera Volcánica Central de Costa Rica. Rev. geol. Amér. Central, 9: 75-98.

ARIAS, O. \& DENYER, P., 1991: Aspectos neotectónicos de Puriscal y alrededores, Costa Rica. - Rev. geol. Amér. Central, 12: 83-95.

ARIAS, O. \& DENYER, P., 1991: Estructura geológica de la región comprendida en las hojas topográfica Abra, Caraigres, Candelaria y Río Grande, Costa Rica. - Rev. geol. Amér. Central, 12: 61-74

ASTORGA, A., FERNANDEZ, J., BARBOZA, G., CAMPOS, L., OBANDO, J., AGUILAR, A. \& OBANDO, L., 1989: Cuencas sedimentarias de Costa Rica: Evolución Cretácico Superior-Cenozoica y potencial de Hidrocarburos. - Symposium on the Energy and Mineral Potencial of the Central American- Caribbean Region, San José, Costa Rica, March 6-9, 1989, Circumpacific Council: 23 págs.

ASTORGA, A., FERNANDEZ, J., BARBOZA, G., CAMPOS, L., OBANDO, J., AGUILAR, A. \& OBANDO, L., 1991: Cuencas sedimentarias de Costa Rica: Evolución geodinámica y potencial de hidrocarburos. - Rev. geol. Amer. Central, 13: 25-59.

BARQUERO, R. \& PERALDO, G. (Eds), 1993: El temblor de Pejibaye de Turrialba del 10 de julio de 1993: aspectos sismológicos, neotectónicos y geotécnicos. - Informe interno Instituto Costarricense de Electricidad, 32 págs.

BOSCHINI, Y., ALVARADO, G. \& ROJAS, W., 1988: El terremoto de Buenavista de Pérez Zeledón (Julio 3, 1983): Evidencia de una fuente sismogénica intraplaca desconocida en Costa Rica. Rev. geol. Amér. Central, 8: 111-121.

BOWIN, C., 1976: The Caribbean Gravity Field and Plate Tectonics. - Geol. Soc. Amer. Special Paper 169, 79 págs.

COLLOT, J. \& FISHER, M., 1991: The Collision Zone between the North d'Entrecasteaux Ridge and the New Hebrides island Arc 1. Sea Bean Morphology and Shallow Structure. - J. Geophys Res, 96B, 3: 4457-4478

DENYER, P. \& ARIAS, O., 1991: Estratigrafía de la región central de Costa Rica. - Rev. geol. Amér. Central, 12: 1-59.

FAN, G., BECK, S. \& WALLACE, T., 1993: The Seismic Source Parameters of the 1991 Costa Rica Aftershock Sequence: Evidence for a Transcurrent Plate Boundary. - J. Geoph Res. 98, B9: 15,759-15,778.

FERNANDEZ, M., 1995: Análisis sísmico en la parte central de Costa Rica y evaluación del hipotético sistema de falla transcurrente de Costa Rica. - Tesis de maestría, Universidad Nacional Autónoma de México (UNAM), 85 págs.

FISHER, D., GARDNER, T., MARSHALL, J. \& MONTERO, W., 1994: Kinematics associated with late Cenozoic deformation in central Costa Rica: Western boundary of the Panama microplate. Geology, 22, 3: 263-266.

FROHLICH, C. \& APPERSON, K., 1992: Earthquake focal mechanisms, moment tensors, and the consistency of seismic activity near plate boundaries. - Tectonics, 11,2: 279296.

GOES, S., VELASCO, A., SCHWARTZ, S. \& LAY, T., 1993: The April 22, 1991, Valle de la Estrella, Costa Rica (Mw=7.7) earthquakes and its tectonics implications: a broadband seismic study. - J. Geophys. Res., 98, B5: 8127-8142.

GÜENDEL, F., 1986: Seismotectonics of Costa Rica: An analytical view of the southern terminus of the Middle America Trench. 1, 
Doctoral Thesis; University of California at Santa Cruz, 57 págs..

GÜENDEL, F. \& PACHECO, J., 1992: The 19901991 seismic secuence across central Costa Rica: evidence for the existence of a microplate boundary connecting the Panama deformed belt and the Middle America Trench. - Eos Trans. Am. Geophys. Un. 73: 399.

HAGEN, R. \& MOBERLY, R., 1994: Tectonic Effects of a Subducting Aseismic Ridge: The Subduction of the Nazca Ridge at the Peru Trench. - Marine Geophysical Researches, 16: 145-161.

JACOB, K., PACHECO, J. \& SANTANA, G., 1991: Seismology and Tectonics in Costa Rica, Earthquake of April 22, 1991. - Reconnaissance Report, Earthquake Spectra, Supplement B, 7: 15-33.

LONSDALE, P. \& KLITGORD, K., 1978: Structure and tectonics of the eastern Panama Basin. - Geol. Soc. Amer. Bull, 89, 7: 981-999

MACHARE, J. \& ORTLIEB, L., 1992: PlioQuaternary Vertical Motions and the Subduction of the Nazca Ridge, Central Coast of Peru. - Tectonophysics, 205: 97-108.

MONTERO, W., 1994: Sismicidad y Neotectónica, En: DENYER, P., KUSSMAUL, S. (eds), 1994: Atlas Geológico Gran Area Metropolitana: 147-160; Ed. Tecnológica de Costa Rica

MONTERO, W, 1994: Neotectonics and related stress distribution in a subduction-collisional zone: Costa Rica. - Profil, 7: 125-141.

MONTERO, W. \& DEWEY, J.W., 1982: Shallow-focus seismicity, composite focal mechanism, and tectonic of the Valle Central de Costa Rica. - Seis. Soc. Amer. Bull, 72: 1611-1626.

MONTERO, W. \& MORALES, L.D., 1984: Sismotectónica y niveles de actividad de microtemblores en el suroeste del Valle Central, Costa Rica. - Rev. Geof., Inst. Panam. Geogr. Hist., 21: 21-41.
MONTERO, W. \& MORALES, L. D., 1988: Zonificación sísmica del Valle Central. - Memorias del $4^{\circ}$ Seminario de Ingeniería Estructural, San José, CR.

MONTERO, W. \& MORALES, L. D., 1990: Deformación y Esfuerzos neotectónicos en Costa Rica. Rev. geol. Amer. Central, 11: 69-87.

MONTERO, W., PANIAGUA, S., KUSSMAUL, S. \& RIVIER, F., 1992: Geodinámica interna de Costa Rica. Rev. geol. Amer. Central, 14: 1-12.

NATIONAL EARTHQUAKE INFORMATION CENTER (NEIC), 1990: Preliminary Determination of Epicenters, December.

NATIONAL EARTHQUAKE INFORMATION CENTER (NEIC), 1991: Preliminary Determination of Epicenters, August

NATIONAL EARTHQUAKE INFORMATION CENTER (NEIC), 1992: Preliminary Determination of Epicenters, March.

OBANDO, L., BOTTAZZI, G. \& ALVARADO, F., 1991: Sedimentología de algunas facies de la Formación Coris (Mioceno MedioMioceno Superior), Valle Central, Costa Rica, America Central. - Rev. geol. Amer. Central, 13: 61-76.

PINDELL, J.L. \& DEWEY, J.F., 1982: PermoTriassic reconstruction of western Pangea and the evolution of the Gulf of Mexico/Caribbean region. - Tectonics, 1: 179212.

PLAFKER, G. \& WARD, S., 1992: Back Arc Thrust Faulting and Tectonic Uplift along the Caribbean Sea Coast During the April 22, 1991 Costa Rica Earthquake. - Tectonics, 11, 4: 709-718.

PONCE, D. \& CASE, J., 1987: Geophysical Interpretation of Costa Rica. En: U.S. Geological Survey Mineral Resources Assessment of the Republic of Costa Rica, U.S. Geol. Surv. Misc. Invest. Folio, I1865: 8-17. 
PROTTI, M., GUENDEL, F. \& McNALLY, K., 1994: The geometry of the Wadati-Bennioff zone under southern Central America and its tectonic significance: result from a highresolution local seismographic network. Phys. Earth Planet. Int., 84: 271-287.

PROTTI, M. \& SCHWARTZ, S., 1994: Mechanics of back arc deformation in Costa Rica: Evidence from an aftershock study of the April 22, 1991, Valle de la Estrella, Costa Rica, earthquake (Mw=7.7). - Tectonics, 13, 5: 1093-1107.

ROJAS, W. \& BARQUERO, R., 1991: El temblor de Piedras Negras. En: BARQUERO, R, BOSCHINI, I., 1991 (eds.): La crisis sísmica del Golfo de Nicoya y eventos sísmicos relacionados, Costa Rica, 1990. Informe de la Red Sismológica Nacional, 152 págs.

STOIBER, R. \& CARR, M., 1971: Recent Volcanisms and Seismicity in Central America. En: Simposium on Volcanism an Upper
Mantle Earthquakes, 27 Int Geol. Geophys., The General Assembly, Moscow, 15: 35 págs.

SUAREZ, G., PARDO, M., DOMINGUEZ, J., PONCE, L., MONTERO, W., BOSCHINI, I. \& ROJAS, W., (1995): The Limón, Costa Rica Earthquake of April 22, 1991: Back arc Thrusting and Collisional Tectonics in a Subduction Environment. - Tectonics, 14, 2: 518-530.

WHITE, R., 1991: Tectonic implications of upper-crustal seismicity in Central America. En: SLEMMONS, D., ENGDAHL, E., ZOBACK, M. \& BLACKWELL, D. (eds.): Neotectonics of North America: Boulder, Colorado, Geological Society of America, Decade Map volume 1.

WHITE, R. \& HARLOW, D., 1993: Destructive Upper-Crustal Earthquakes of Central America Since 1900. - Bull. Seism. Soc. Am., 83, 4: 1115-1142. 